\title{
Miningo
}

http://dx.doi.org/10.1590/0370-44672018720117

Bruna Camara Trampus ${ }^{1,2}$

https://orcid.org/0000-0002-0468-0205

Silvia Cristina Alves França ${ }^{1,3}$

https://orcid.org/0000-0003-2645-9007

1CETEM - Centro de Tecnologia Mineral (Centre for Mineral Technology), Rio de Janeiro - RJ, Brasil

E-mails: ${ }^{2}$ btrampus@cetem.gov.br,

3sfranca@cetem.gov.br

\section{Rheology applied to the environmental management of mineral tailings: focus on safer disposal and water reuse}

\begin{abstract}
Mining activities worldwide are subject to serious geotechnical accidents involving tailings dams. Therefore, many studies have focused on tailings dewatering before their deposition. This article studies the rheological properties of flocculated and thickened nickel tailings in order to determine the effect of the initial solid concentration and type of rheology modifying agents (two anionic polymeric flocculants) on their stability for disposal in dams. The sediment was submitted to rheological tests, with the vane technique, and slump tests, to obtain information about static and dynamic yield stress and slump height, respectively. The results showed a strong influence of the initial solid concentration and the polymeric flocculant on the particle aggregation. Both particle cohesion and yield stress of the sediment increased, reaching static yield stress of around 1,400 Pa. Both flocculants were efficient in thickening by batch sedimentation, allowing water recycling in the range of $70-90 \%$ with turbidity less than 100 NTU and the production of sediment with static yield stress much higher than specified for mineral paste.
\end{abstract}

keywords: rheology; yield stress; mineral paste; water recycling; nickel tailings.

\section{Introduction}

The mining industry is one of the main contributors for the production of raw materials used to manufacture goods in a wide range of sectors. As resource consumption continues to increase, mining has become one of the most important economic activities. However, ore processing demands large volumes of water and generates an enormous amount of tailings, which are commonly deposited as slurries with a low percentage of solids in tailings dams (not adequate term) (Sofrá and Boger, 2002; Boger, 2009). Improper tailings management can lead to the release of millions of cubic meters of slurry (mineral pulp), and cause serious disasters, such as the Fundão tailings dam failure at the Samarco mine in Brazil on November $5^{\text {th }}, 2015$ and the partial dam failure at the Tonglvshan mine in China on March $12^{\text {th }}$, 2017 (Wise Uranium Project, 2017). As a result, tailings thickening or dewatering before deposition makes disposal of these tailings in the environment safer, besides allowing partial recovery of process water and reduction of the volume of tailings and the area required for storage. However, this increases the difficulties and production costs (Sofrá and Boger, 2002, 2011; Boger, 2009, 2013).

Mineral pastes are defined as homogeneous and dense material with low or no free water level, without particle size segregation, and a laminar flow with positive displacement pumps (Sofrá and Boger, 2002; Boger, 2013). The difference between pastes and thickened tailings is determined by yield stress, which measures the ability of the tailings to withstand deformation. Pastes are thickened tailings with a lower limit of the yield stress of $200 \mathrm{~Pa}$ (Clayton et al., 2003; Boger, 2013; Fitton and Seddon, 2013). Thus, a good understanding of the rheological properties of paste is important for the mining industry.

The solid waste paste filling technology was introduced at the mining with cemented backfill. Therefore, the addition of different cementitious materials to the mineral tailings, decrease the volume of tailing, but increases the costs (Deng et al., 2017). However, previous studies have investigated the use of rheology modifying agents, such as water-soluble polymers with high molecular weight, for the production of thickened tailings and pastes (Dias et al., 2004; Gadelha and França, 2015). The existence of polymer-slurry interaction enables the formation of flocs, which are irregularly shaped aggregates with liquid in their structures. Their characteristics are highly dependent on the type of polymer-slurry interaction and the floc formation process (Dias et al., 2004; Jarvisa et al., 2005). Therefore, the yield stress is strongly dependent on the dosage and polymer structure as well as tailings characteristics, such as particle size and shape, solids concentration, surface charge density, solid density, bulk density and $\mathrm{pH}$ (Sofrá and Boger, 2011; Parsapour et al., 2014; Wu et al., 2015).

This paper reports the development of a flocculant system for the mining industry that can simultaneously target several properties, such as the solid-liquid separation process, water recovery (qualitative and quantitative) and paste formation 


\section{Materials and methods}

The materials and experimental procedure were based on the data obtained by Andrade (2016) for flocculation and

\subsection{Materials}

The material used in the experimental study was a tailings sample produced by the flotation of nickel sulphide ore, obtained from a tailings dam in the state of Minas Gerais.

The flocculants studied were two

\subsection{Tailings characterization}

The nickel tailings were characterized according to the particle size distribution by laser diffraction, with a Malvern Mastersizer 2000.

The average particle electrophoretic mobility was used to calculate the zeta potential (Lima and Luz, 2007; thickening of nickel tailings. Pulps were studied with solid concentration (C0) from 10 to $23 \%$ (w/w) and were submitted to flocculation and batch sedimentation tests in order to obtain information about sediment cohesion.

literature data obtained by Andrade (2016), they were used at the dosage of $80 \mathrm{~g} / \mathrm{t}$ of dry solids. This is the minimum dosage to obtain appropriate turbidity of the supernatant and sedimentation rate.

Bárány et al., 2011), since the nickel tailings are composed of a mixture of particles of different mineralogical species. $10 \%(\mathrm{w} / \mathrm{w})$ solid slurries were prepared with $\mathrm{KCl}$ indifferent electrolytes (0.01 and $0.001 \mathrm{M})$. The measurements were conducted at room

\subsection{Preparation of thickened flocculated tailings}

The pulps were prepared with nickel tailings and tap water, flocculated in a Jar Test equipment and transferred to a $2 \mathrm{~L}$ graduated cylinder for batch sedimentation. The flocculant solution was then added to the slurry and stirred at $300 \mathrm{rpm}$ for $1 \mathrm{~min}$, followed by slow stirring at 150

rpm for 2 min. Considering the importance of shear rate and solids concentration in the flocculation rate, the operational conditions can be expressed in terms of Camp number (time $[\mathrm{s}] \mathrm{x}$ shear gradient [s-1]), given respectively by $\mathrm{C}_{\text {fast }}=33,000$ and $\mathrm{C}_{\text {slow }}=21,600$.

\subsection{Thickened tailings characterization \\ 2.4.1 Slump test}

The slump test is a technique standardized and is conventionally used to determine the consistency of fresh concrete. This technique is applied with conical geometry. However, according to the results of various studies, adaptation to cylindrical geometry can be used to evaluate the consistency of mineral suspensions
(Pashias et al., 1996; Clayton et al., 2003; Osorio et al., 2008; Boger, 2009; Mizani and Simms, 2016).

The experimental procedure of this study can be observed in Figure 1 , in which a small PVC cylinder (radius $=$ height $=53 \mathrm{~mm}$ ) is filled with bottom sediment from the graduated

$$
\begin{gathered}
h=H-H s \\
\% S H=(h / H) \times 100
\end{gathered}
$$
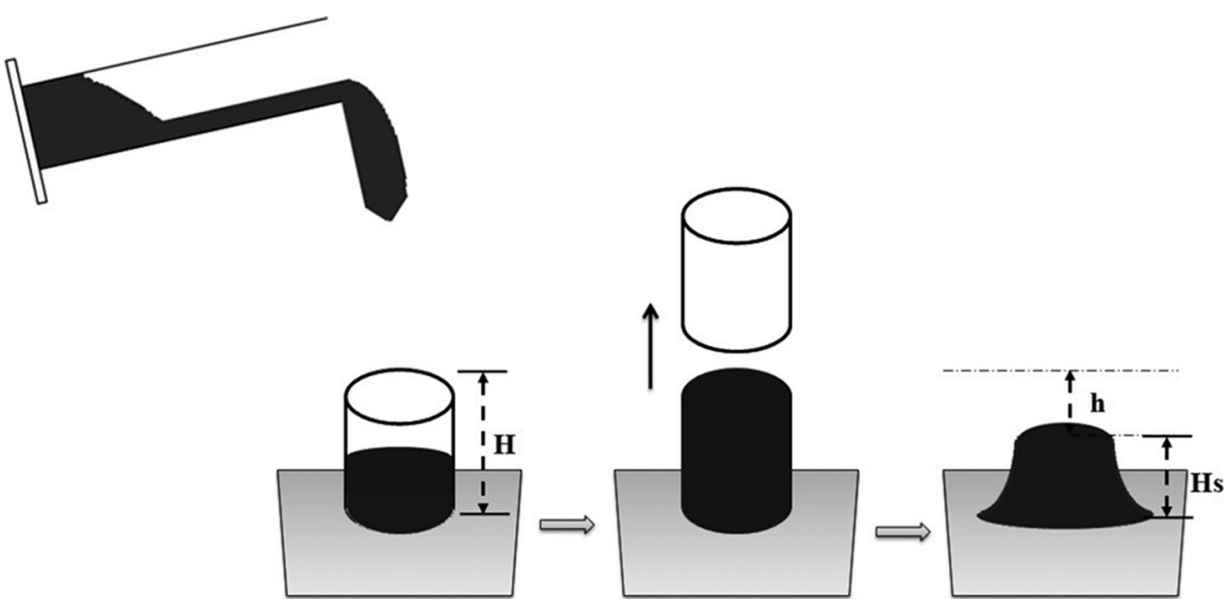

temperature and $\mathrm{pH}$ range of 2 to 12 , adjusted with $\mathrm{KOH}$ and $\mathrm{HCl}$ dilute solutions, using a Malvern ZetaSizer Nano ZS (Malvern Instruments Inc.). The zeta potential was calculated using the experimentally-determined data and the Henry's model.

The flocculated pulp was transferred to the graduated cylinder, and was set aside undisturbed for $24 \mathrm{~h}$. After that, the supernatant liquid was removed and the sediment (underflow) was studied to determine its properties, with the equipment and techniques presented in the items that follow.

cylinder and then removed vertically to allow the material to slump under its own weight. Therefore, it is possible to calculate the height difference between the cylinder and the sediment (Equation 1), and the slump height (SH) (Equation 2). This provides an empirical measurement of tailings consistency.

Figure 1

Schematic of slump test with cylinder. 


\subsubsection{Shear rheology}

Yield stress $\left(\tau_{0}\right)$ can be estimated from different rheometry techniques. All $\tau_{0}$ data presented in this study were obtained using the vane technique, to eliminate slip (Boger, 2009, 2013; Sofrá and Boger, 2011). Two measurement techniques were used to obtain the $\tau_{0}$ : direct method and regression method based on

Where, $\tau_{0}$ is the H-B YS, $K$ is the fluid consistency index, and $\mathrm{n}$ is the flow behavior index.

Thus, in this study, the $\tau_{0}$ was obtained for the bottom and top sediments of the graduated cylinder with a Haake RheoStress 1 rotational rheometer, and the experimental procedure was performed in three stages at room tempera-

\subsubsection{Sediment concentration analysis}

The sediment concentration $\left(\mathrm{C}_{\text {sed }}\right)$ was obtained indirectly by a moisture analyzer, OHAUS, model

\section{Results and discussion}

\subsection{Nickel tailings characterization}

From Figure 2(a), it can be observed that the nickel tailings presented a very fine particle size. Particles smaller than $28.3 \mu \mathrm{m}$ accounted for $90 \%, 5.9 \mu \mathrm{m}$ accounted for $50 \%$ and

Figure 2

Nickel tailings

characterization: (a) particle size distribution; (b) net surface charge of the particles. the flow curve results. The direct method determines the $\tau_{0}$ value by the measurement of a single point, avoiding the need to extrapolate flow data. In this method, basically the torque is observed as a function of time and increases until reaching a maximum value. The maximum torque value obtained is when the material yields,

$$
\tau=\tau_{0}+K_{h} \dot{\gamma}^{n_{h}}
$$

ture. First, the sediment's (bottom and top samples) yield stress was obtained by the direct method applying a constant shear rate of $0.1 \mathrm{~s}^{-1}$ for a maximum time of 300 s. These data are referred to as static $\tau_{0}$. After this, the sediment was subjected to a constant high shear, $400 \mathrm{rpm}$, in order to destroy the floc structure and release the contained water. This new sediment had

MB23. Therefore, after the rheological analysis, the sample was transferred to the moisture analyzer and and it is equivalent to the $\tau_{0}$. In this work, the Herschel-Bulkley model (H-B) (Equation 3), which is more appropriate to describe the flow curve of thickened tailings, was used to fit the experimental results and obtain the $\tau 0$ by regression (Nguyen and Boger, 1983, 1998; Sofrá and Boger, 2002, 2011; Boger, 2009, 2013).

its yield point analyzed by both methods and is referred to as dynamic $\tau_{0}$. The direct method was the same as the previous one, and for plotting the flow curve, the shear rate and shear time were defined as 0.01 to $100 \mathrm{~s}^{-1}$ and $5 \mathrm{~min}$ per point. The analysis of sediment $\tau_{0}$ after high shearing intends to evaluate the maximum floc destruction due to pipeline transport.

subjected to heating, allowing percent solid determination. finer than $1.3 \mu \mathrm{m}$ represented $10 \%$ of the total amount of tailings. This particle fineness associated with strong electrostatic repulsion in natural $\mathrm{pH}$ $(7 \leq \mathrm{pH} \leq 8)$ (Figure $2 \mathrm{~b})$, impairs the

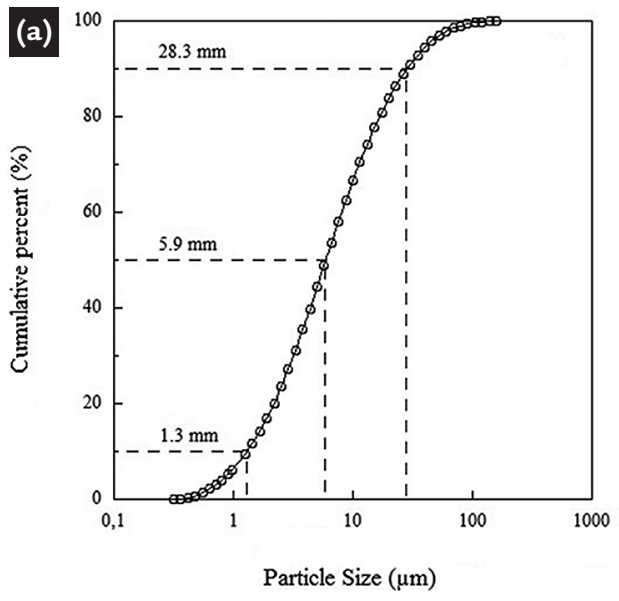

\subsection{Thickened tailings characterization}

The laboratory-scale batch sedimentation tests (graduated cylinder) were carried out to determine the performance of paste thickeners under the established conditions, by obtaining data on the thickener underflow characteristics. $\tau_{0}$ and $\mathrm{C}_{\text {sed }}$ obtained from the various techniques, polymeric flocculants (R-10 and $\mathrm{R}-90$ ), and $\mathrm{C}_{0}$ (in the range of 10 to
$23 \% \mathrm{w} / \mathrm{w})$, can be observed in Figures 3 and 4 . As reported in literature, there was a variation of the $\mathrm{C}_{\text {sed }}$ in the sediment compaction zone, and the flow properties of concentrated mineral suspensions varied significantly with $\mathrm{C}_{\text {sed }}$ (França et al., 1999; Sofrá and Boger, 2002; Boger, 2013). In this study, the flocculated and thickened sediment presented a concen- natural sedimentation process (Sofrá and Boger, 2011). However, the presence of fine material is indispensable for paste formation. Thus, the need exists to use flocculants.

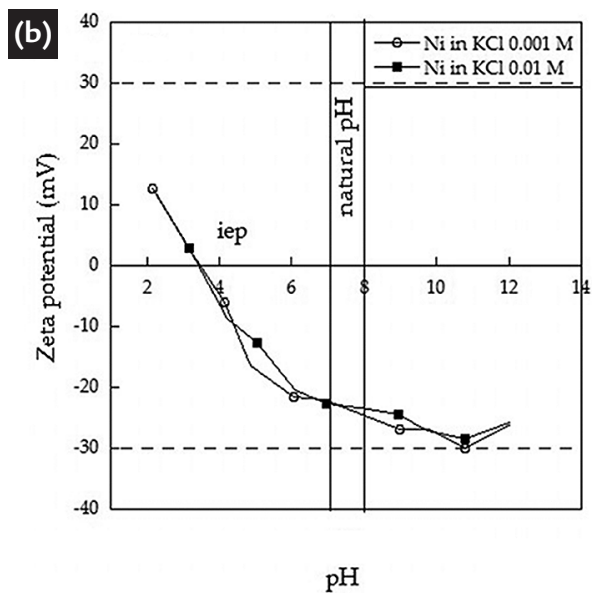

tration variation of up to $28 \% \mathrm{w} / \mathrm{w}$ between top and bottom. Figure 3 (a) shows the increase of the static and dynamic $\tau_{0}$ for the bottom sediment relationship to the top. This behavior is due to the existing concentration gradient, thus allowing the acquisition of data on $\tau_{0}$ in the limit conditions of each case analyzed. Figure 3 (a) also shows that the measurement 
techniques used (direct method and by regression) produced very similar values, even with the difficulties in reaching such low shear rates. Figure 3 (b) illustrates the strong dependence of the $\tau_{0}$ on the $\mathrm{C}_{0}$ and the flocculating polymer type. The increase in $\mathrm{C}_{0}$ led to growth of the sediment $\tau_{0}$. This occurred because the difference in the $\mathrm{C}_{0}$ influences the shape

(a)

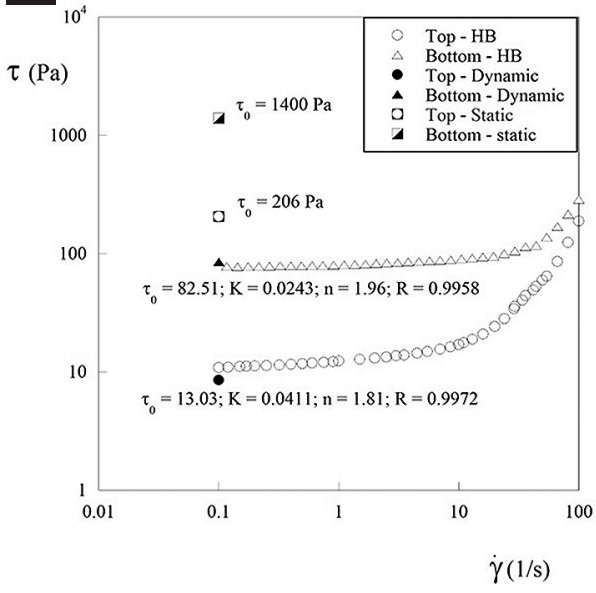

The curves presented in Figure 4 show the same trends as those presented in several other studies (Nguyen and Boger, 1998; Sofrá and Boger, 2002, 2011; Boger, 2013), i.e., the exponential growth of $\tau_{0}$ with $\mathrm{C}_{\text {sed }}$. The static $\tau_{0}$ (Figure 4-a) has values higher than $200 \mathrm{~Pa}$ for $\mathrm{C}_{\text {sed }}$ greater than 47 and $50 \%(\mathrm{w} / \mathrm{w})$, flocculated with R-10 and R-90 respec-

(a)

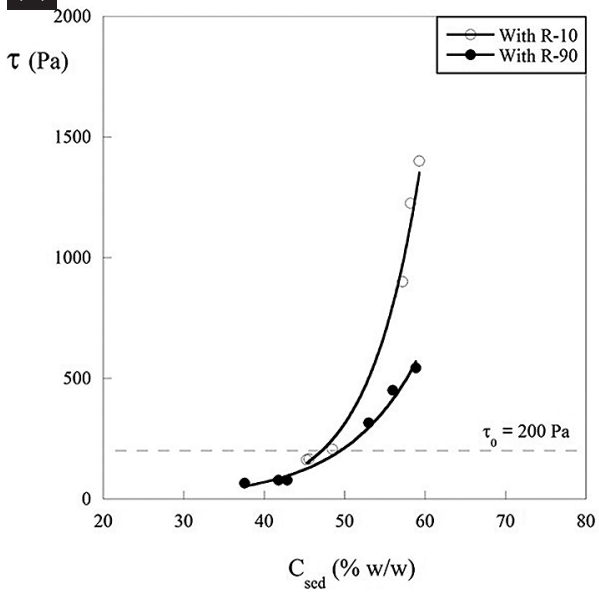

An example of the slump test is shown in Figure 5, and Figure 6 illustrates the strong relationship of the static and dynamic $\tau_{0}$, Csed and slump height. The data in Figure 5 indicate the same trends as those presented in other studies (Pashias et al., 1996; Clayton et al., 2003; Osorio et al., 2008; Boger, and structure of the flocs formed, and consequently the settling velocity and sediment cohesion (Jarvisa et al., 2005; Sofrá and Boger, 2011; Parsapour et al., 2014). Between the two polymers, R-10 reached higher values of static and dynamic $\tau_{0}$, reaching $1400 \mathrm{~Pa}$ and $83 \mathrm{~Pa}$, respectively, for pulps with $23 \%(\mathrm{w} / \mathrm{w})$ of $\mathrm{C}_{0}$. The different efficiencies between

\section{(b)}

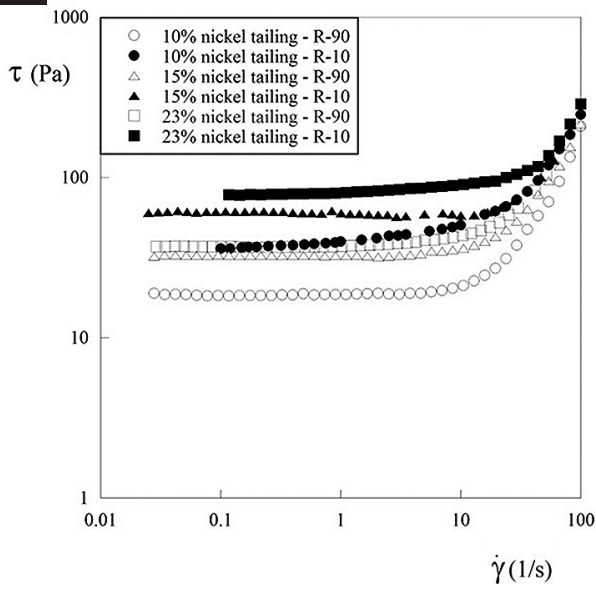

tively. These data are of great importance because they are used for rake design in thickeners and for pump restart and design (Boger, 2009).

It can be observed that for all cases studied the underflow had static $\tau_{0}$ above that specified for pastes. However, it can be seen in Figure 4 (b) that the dynamic $\tau_{0}$ reached maximum values of 82.5 and

\section{(b)}

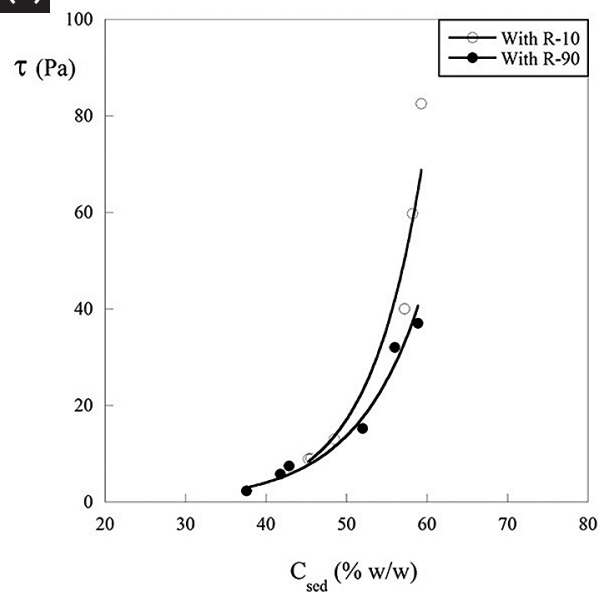

2009; Deng et al., 2017; Mizani and Simms, 2016), i.e., an inverse relationship of $\% \mathrm{SH}$ with $\tau_{0}$ and $\mathrm{C}_{\text {sed }}$. Figure 6 (a) evidences that the use of polymer R-10 as a flocculant allowed the formation of more cohesive sediments, that is, with higher values of static $\tau_{0}$ and lower values of $\% \mathrm{SH}$, reaching $\mathrm{SH}=12 \%$. the studied polymers can be explained by the existing polymer-slurry interaction difference, i.e., interaction type (bridging particle flocs or neutralized charge particle flocs), floc size and other aspects (Jarvisa et al., 2005; Sofrá and Boger, 2011). However, for better understanding, it is necessary to elucidate the polymers' structures and characteristics.

Figure 3

Flow behavior for the thickened nickel tailings. (a) for the top and bottom sediment of the pulp with $\mathrm{C}_{0}$ of $23 \%(w / w)$ and flocculated with the polymer R-10; (b) only dynamic $\tau_{0}$ for the sample from the bottom sediment.

$37 \mathrm{~Pa}$, with $\mathrm{R}-10$ and $\mathrm{R}-90$ respectively, indicating that in the case of complete destruction of the flocs, the thickened tailings do not achieve paste consistency. However, for paste transportation, a positive displacement pump is used instead of a centrifugal pump. Thus, it is certain that the floc destruction will be much less intense.

Figure 4

$\tau_{0}$ as a function of

$\mathrm{C}_{\text {sed }}$. (a) static $\tau_{0}$; (b) dynamic $\tau_{0}$.

Figure 6 (b) allows comparison of the $\tau_{0}$ and $\% \mathrm{SH}$ of the sediment before and after shearing, that is, before and after the breaking of the flocs. It can be observed that the breaking of the flocs released the contained water, abruptly reducing the sediment consistency, increasing $\% \mathrm{SH}$ and reducing $\tau_{0}$. 
Figure 5

Slump test for the sediment formed with C0 of the $23 \%$ and $80 \mathrm{~g} / \mathrm{t}$ R- 10 .

Figure 6 Relationship between the $\tau_{0}, \mathrm{C}_{\text {sed }}$ and $\% \mathrm{SH}$. (a) static $\tau_{0}$; (b) dynamic and static $\tau_{0}$ for polymer R-10.

The flocculation and sedimentation of the nickel tailing allowed a water recovery up

\section{Conclusion}

This article presented and discussed the effect of initial solid concentration and polymeric flocculant type on the cohesion of nickel tailings. Both flocculants were efficient in thickening by batch sedimenta-

\section{Acknowledgments}

The authors would like to thank The National Council for

\section{References}
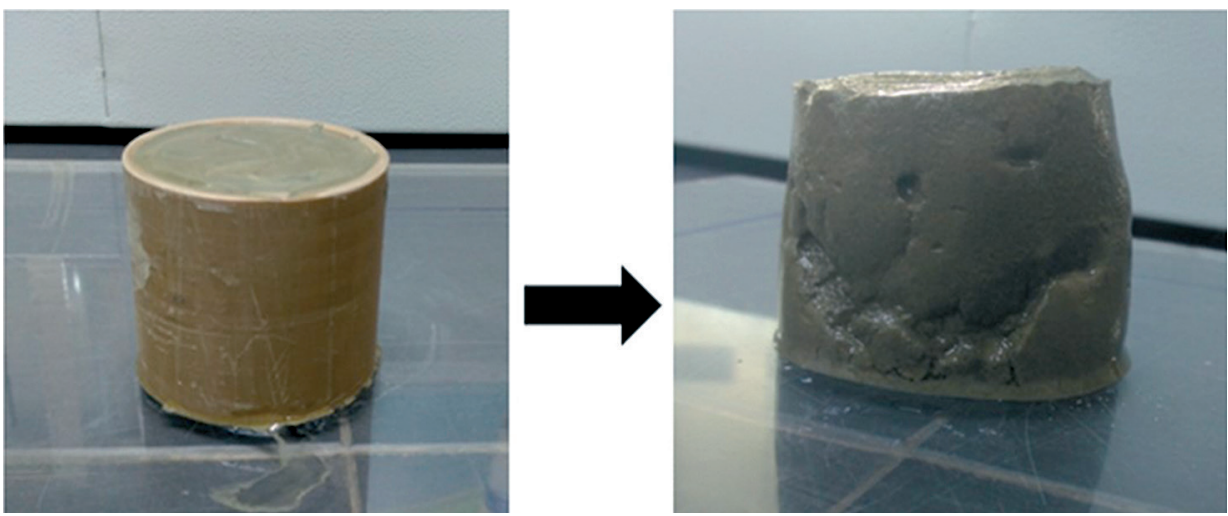

(a)
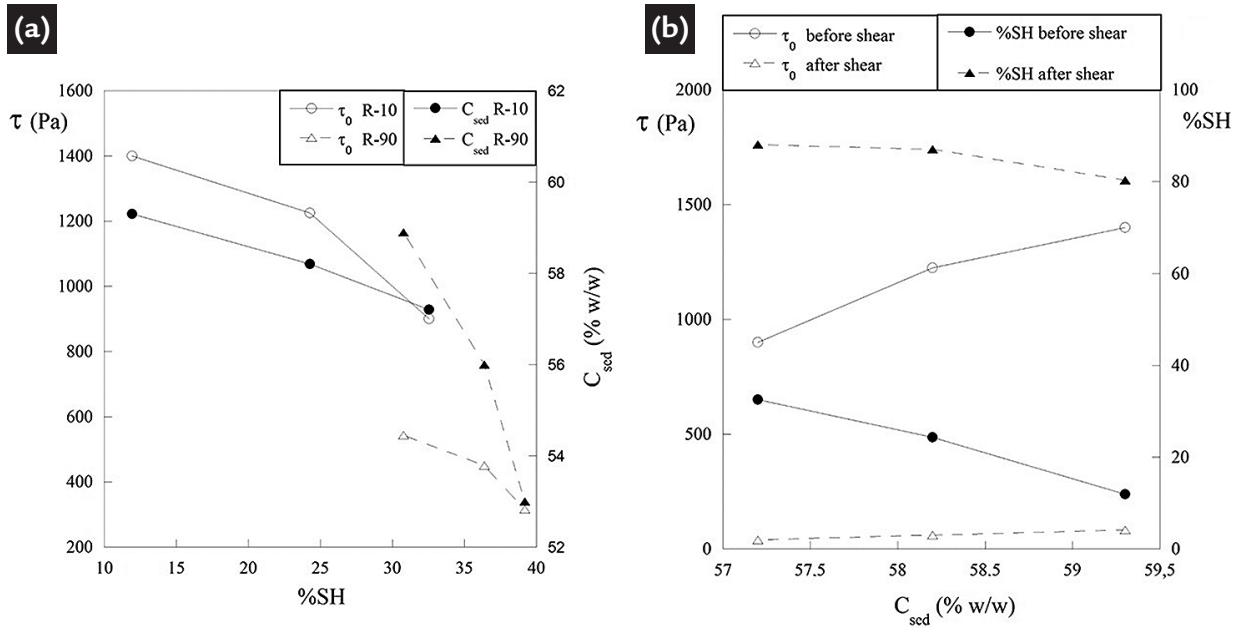

to $90 \% \mathrm{w} / \mathrm{w}$. In all cases studied, recovered water presented turbidity less than 100 NTU

that according to the Brazilian standards, allows its reuse or disposal in the environment. tion, causing an increase in $\mathrm{C}_{\text {sed }}$ with increase in $\mathrm{C}_{0}$, and consequently, increase of $\tau_{0}$ and reduction of $\% \mathrm{SH}$. In other words, they allowed the production of more cohesive and stable sediments. Therefore, the results provide the mining company a new alternative for the management of their tailings, allowing its disposition in the form of paste and a process water recovery with turbidity less than 100 NTU.
Scientific and Technological Development (CNPq) for financial support through CT-Universal 2016 (Process $\left.n^{\circ} 421710 / 2016-0\right)$.

ANDRADE, L. S. Desaguamento de polpas minerais floculadas (Dewatering of mineral flocculated slurries). Rio de Janeiro: Universidade Federal do Rio de Janeiro, 2016. 52 p. (Trabalho de Conclusão de Curso de Engenharia Química- Undergraduate final project - Chemical engineering).

BÁRÁNY, S., MESZAROS, R., MARCINOVA, L., SKVARLA, J. Effect of polyelectrolyte mixtures on the electrokinetic potential and kinetics of flocculation of clay mineral particles. Colloids and Surfaces A: Physicochemical and Engineering Aspects, v. 383, p. 48-55, 2011.

BOGER, D. V. Rheology and the resource industries. Chemical Engineering Science, v. 64, p. 4525-4536, 2009.

BOGER, D. V. Rheology of slurries and environmental impacts in the mining industry. The Annual Review of Chemical and Biomolecular Engineering, v. 4, p. 239257, 2013.

CLAYTON, S., GRICE, T. G., BOGER, D. V. Analysis of the slump test for on-site 
yield stress measurement of mineral suspensions. International Journal of Mineral Processing, v. 70, p. 3-21, 2003.

DENG, D. Q., LIU, L., YAO, Z.L., SONG, K. I.-I. L., LAO, D. Z. A practice of ultra-fine tailings disposal as filling material in a gold mine. Journal of Environmental Management, v. 196, p. 100-109, 2017.

DIAS, C. L. P., SILVA, L. M., PERES, A. E. C., VALADÃO, G. E. S. Utilização de reagentes auxiliares na filtragem (Use of chemical filter aids). REM - Revista Escola de Minas, v. 57, n. 4, p. 229-234, 2004.

FITTON, T.G., SEDDON, K.D. Paste and thickened tailings - myth busting and clarification. In: INTERNATIONAL SEMINAR ON PASTE AND THICKENED TAILINGS (PASTE 2013), 16, 2013. Belo Horizonte. Proceedings of Paste 2013. Belo Horizonte: Australian Center of Geomechanics, 2013, p. 37-43.

FRANÇA, S. C. A., BISCAIA JR., E. C., MASSARANI, G. Study of batch sedimentation simulation - establishment of constitutive equations. Powder Technology, v. 101, p. 157-164, 1999.

GADELHA, T. S., FRANÇA, S. C. A. Polymer assessment for dewatering and filtration of nickel ore tailings. In: INTERNATIONAL SEMINAR ON ENVIRONMENTAL ISSUES IN MINING (ENVIROMINE 2015), 4, 2015. Lima. Proceedings of Enviromine 2015. Lima: Gecamin Publications, 2015, 15ENV_C0505.

JARVISA, P., JEFFERSONA, B., GREGORYB, J., PARSONS, S. A. A review of floc strength and breakage. Water Research, v. 39, p. 3121-3137, 2005.

LIMA, R. M. F., LUZ, J. A. M. Mobilidade eletroforética (Electrophoretic mobility). In: SAMPAIO, J.A., FRANÇA, S.C.A., BRAGA, P.F.A. (Eds.). Tratamento de minérios - práticas laboratoriais (Ore beneficiation - laboratory procedures). Rio de Janeiro:CETEM/MCT, 2007. cap. 9, p. 507-530. 557 p.

MIZANI, S., SIMMS, P. Method-dependent variation of yield stress in a thickened gold tailings explained using a structure based viscosity model. Minerals Engineering, v. 98, p. 40-48, 2016.

NGUYEN, Q. D., BOGER, D. V. Yield stress measurement for concentrated suspensions. Journal of Rheology, v. 27, p. 321-349, 1983.

NGUYEN, Q. D., BOGER, D. V. Application of rheology to solving tailings disposal problems. International Journal of Mineral Processing, v. 54, p. 217-233, 1998.

OSORIO, C. A. H., ARAUJO, A. C., VALADÃO, G. E. S. Estudo de características de algumas pastas minerais (Study of characteristics of some mineral pastes). Tecnologia em Metalurgia e Materiais, v. 4, n. 3 p. 50-55, 2008.

PARSAPOUR, G. A., HOSSININASAB, M., YAHYAEI, M., BANISI, S. Effect of settling test procedure on sizing thickeners. Separation and Purification Technology, v. 122, p. 87-95, 2014.

PASHIAS, N., BOGER, D. V., SUMMERS, J., GLENISTER, D. J. A fifty cent rheometer for yield stress measurement. Journal of Rheology, v. 40, p. 1179-1189, 1996.

SOFRÁ, F., BOGER, D. V. Environmental rheology for waste minimisation in the minerals industry. Chemical Engineering Journal, v. 86, p. 319-330, 2002.

SOFRÁ, F., BOGER, D. V. Rheology for thickened tailings and paste - history, state-of-the-art and future directions. In: INTERNATIONAL SEMINAR ON PASTE AND THICKENED TAILINGS (PASTE 2011), 14, 2011. Perth. Proceedings of Paste 2011. Perth: Australian Center for Geomechanics, 2011, p. 121-134.

WISE URANIUM PROJECT. Chronology of major tailings dam failures. Publishing PhysicsWeb. http://www.wise-uranium.org/mdaf.html (access 2017, december 15).

WU, A., WANG, Y., WANG, H. Estimation model for yield stress of fresh uncemented thickened tailings: coupled effects of true solid density, bulk density, and solid concentration. International Journal of Mineral Processing, v. 143, p. 117-124, 2015.

Received: 9 August 2018 - Accepted: 26 November 2018. 